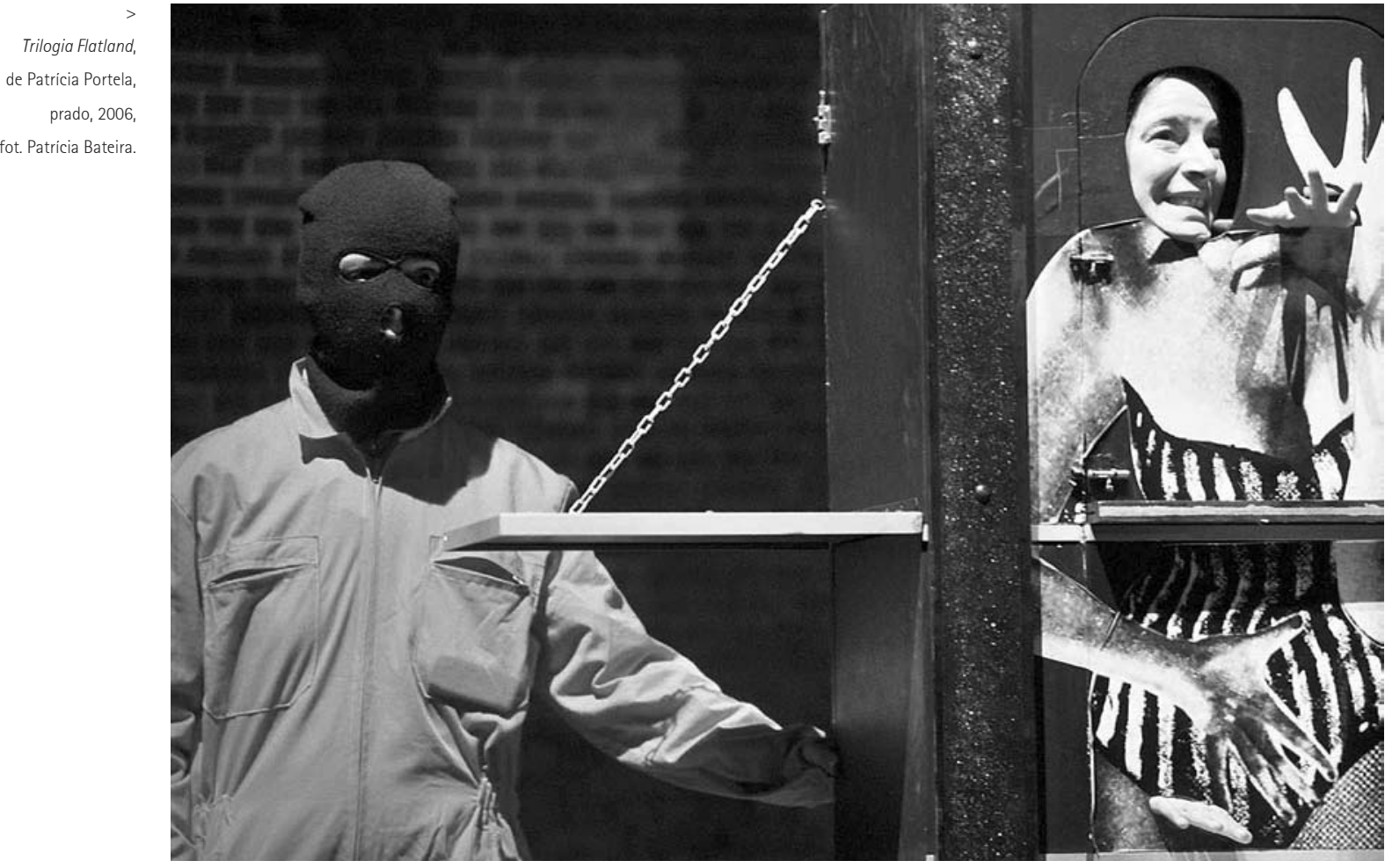

Ana Pais

\title{
Refazer o deslumbramento da decifração Trilogia Flatland, de Patrícia Portela
}

\author{
Ana Pais
}

Cada um que lê reúne-se a uma imensidade pensante, em repouso, quem lê está em estado de levitação, pertence a uma imagem pairante. Maria Filomena Molder (1999: 17)

Uma das maiores dificuldades do nosso tempo é a de saber distinguir o essencial - a felicidade de participar no mundo - do acessório - as crenças e condições relativas a essa participação. Significativamente, esta é uma das consequências da sociedade da informação em que vivemos e através da qual acedemos ao mundo. Estigmatizado por uma noção de espectacularidade instrumentalizada pelos media, o mundo contemporâneo vive numa dimensão de realidade filtrada misturando, frequentemente, factos com leituras de factos, coisas com as imagens das coisas. Os media são, portanto, fabricadores de realidades. Na trilogia Flatland, Patrícia Portela mostra-nos que, muito provavelmente, sempre foi assim, apenas o modo como se fabrica o real vai mudando ao longo dos tempos, cabendo-nos a nós a vigilante procura de uma verdade interior. Com inventividade luminosa, ela mostra-nos o essencial.

Crítica dos processos mediáticos mas também consciente da ancestral capacidade criadora do fazer artístico, Patrícia Portela concebeu um espectáculo sobre a realidade e a aparência, sobre os modos como criamos o real com várias camadas de leitura e fruição: desde a mais imediata - a história do Homem Plano - até a uma abrangente visão da condição contemporânea - a mediatização existencial -, tocando em aspectos candentes relativos ao próprio acontecimento teatral - mediação tecnológica, presença do actor em cena ou não, o estatuto do espectador, etc. Num surpreendente e inesgotável jogo de elementos - palavra, imagem, espaços, interpretação -, Flatland cativa-nos pela simplicidade com que aborda temas complexos e, ao mesmo tempo, pela complexidade com que relaciona trivialidades (ou aparentes trivialidades) com assuntos fundamentais, entretecidos numa imbrincada estrutura narrativa.

0 segredo deste espectáculo reside na ligação, tão excepcional quanto imprescindivel, estabelecida entre os seus vários materiais cénicos. Justamente por isso, o Júri convidado pela Associação de Críticos de Teatro para eleger o Prémio da Crítica 2006 galardoou Flatland com uma Menção Especial pela sua dramaturgia. Dividindo-se em três episódios estreados entre 2004 e 2006, em Portugal e na Bélgica, a trilogia Flatland apresentou-se pela primeira vez em Lisboa, no Centro Cultural de Belém, em Junho de 2006, no âmbito do Alkantara Festival. Apesar já serem conhecidas as duas primeiras partes, a sua apresentação conjunta evidenciou um traço estrutural marcante para a sua dramaturgia: Flatland é uma unidade, um tríptico com um ritmo interino próprio, cujas partes são indissociáveis. Para além do inequívoco talento e erudição de Patrícia Portela, aquilo que destaca este espectáculo e sustenta, na prática, a elaboração teórica de Flatland é o seu conceito dramatúrgico. Este consiste em demonstrar 

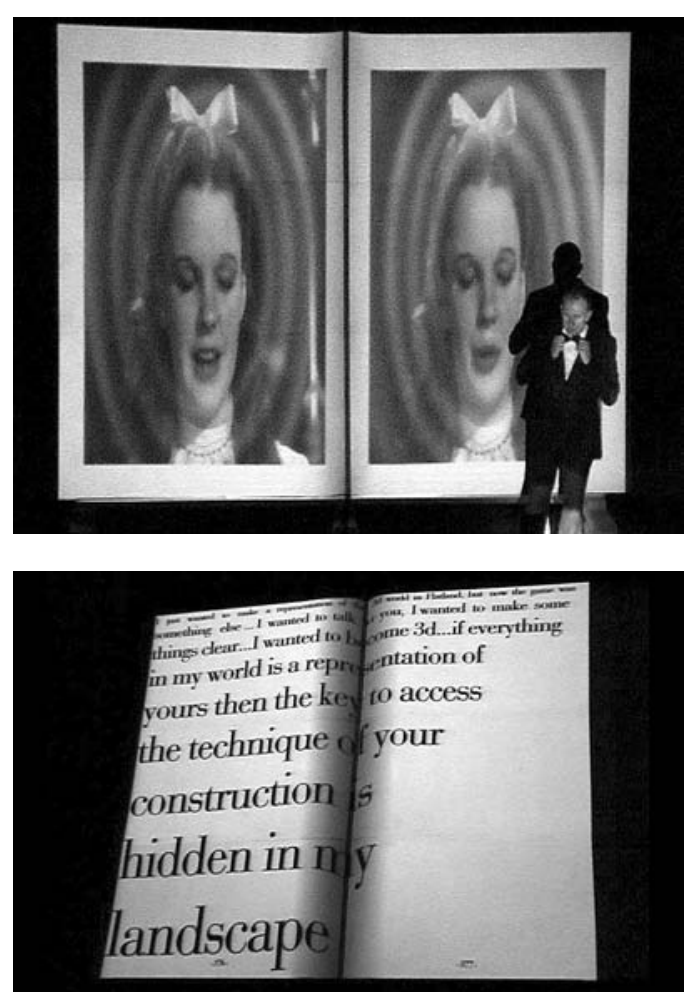

como as fronteiras entre a realidade e a ficção são humanamente instáveis colocando em cena, a todo o instante, essa mesma instabilidade: por um lado, no jogo de níveis de ficção dentro da narrativa e, por outro, entre os níveis de realidade ficcional estabelecidos com o público e com os espaços cénicos. A ambiguidade regula a fluidez dos vários planos: a ficção narrativa (o Homem Plano e o seu desejo de realidade que interfere com a realidade do público), a realidade do acontecimento teatral (os espaços cénicos e as experiências proporcionadas ao público), o cruzamento entre teatro e terrorismo (raptos ficcionais e raptos reais), a relação fundadora entre a palavra e a imagem como criadoras de realidade e ficção simultaneamente.

Quando exibidas na sua totalidade, a trilogia ganha o seu sentido pleno. Só depois de conhecermos a história do Homem Plano e o seu conceito de realidade ("ser é ser visto") faz sentido acontecer um rapto (real e simulado) do público que permita integrar outras realidades como a do terrorismo associado ao teatro, pelos mecanismos próprios da espectacularidade deste último. Basta recordar a queda apoteótica das torres gémeas para duplicar as ambiguidades desta associação. Este efeito é sublinhado pela participação ambigua do espectador enquanto "vítima", ainda que tendo acordado contratualmente essa posição e sendo sempre entretido, alimentado, bem tratado, e até, dissimuladamente salvo. Só depois de "salvo" poderá fazer sentido depositar o espectador-vítima numa grande salade-estar, com cafés e cházinhos, perante as imagens de noticiários televisivos que reportam e apresentam como reais os acontecimentos que o próprio público presenciou, entregue à realidade que diariamente é criada para ele, no seu quotidiano.

Para compreendermos a pujança deste conceito uno, torna-se necessário olhar com maior profundidade os recursos utilizados na criação dessa teia de sentidos, que produz efeitos específicos para o espectador. Este, não só
Trilogia Flatland, de Patricia Portela, prado, 2006, fot. Giannina Urmeneta Ottiker. tem o privilégio de se medir pelo nível de leitura que escolhe fazer do espectáculo, como também (e talvez este seja o único plano em que é uma "vítima inocente") o de participar num acontecimento artístico. Existe uma porta principal de acesso a esse labirinto de experiências e o espectador traz consigo a chave-mestra: o imaginário da infância, ao qual é associado o deslumbramento da decifração que a leitura institui.

No início, era o livro e uma personagem, o Homem Plano (Anton Sckrzypiciel) que, inquieto pela descoberta da realidade em três dimensões, procura uma forma de sair da sua história para existir "realmente". Neste primeiro episódio, não vemos, porém, o actor em cena; escutamos somente a sua voz, o que nos aproxima, quer das origens remotas de uma teatralidade centrada na palavra, quer da voz interior da leitura silenciosa. Em todo o caso, remete-nos para uma voz que fala a partir de um único lugar cénico, um livro gigante, onde imagens e palavras são projectadas. Nada acontece a não ser o próprio contar da história do Homem Plano, tornado acontecimento principal já que as páginas do livro não nos aparecem cheias de letras, como é hábito, mas vão surgindo à medida do discurso oral. É "como se" ouvíssemos a voz do autor, "como se" presenciássemos o momento criativo de escrita, o momento íntimo e secreto, por excelência. Nesse instante, o lugar do espectador é também o lugar do leitor, pois o livro a cuja narrativa assistimos aparece-nos "como se" estivesse a acontecer naquele preciso momento, "como se" fosse um espectáculo que, por acaso, até é. Ao estabelecer este paralelismo entre aquele que vê e aquele que lê, Patricia Portela coloca o espectador na dupla condição de decifrador, da escrita e do espectáculo, convocando, assim, a ancestral concepção do mundo como um livro. De páginas abertas, o mundo-livro ofereciase ao conhecimento daqueles que fossem capazes de o decifrar, de reconhecer códigos e reproduzi-los. E não será por acaso que a descoberta da leitura acontece, por regra,

\author{
Trilogia Flatland, \\ de Patricia Portela, \\ prado, 2006, \\ fot. Giannina Urmeneta \\ Ottiker.
}


Trilogia Flatland, de Patricia Portela,

prado, 2006,
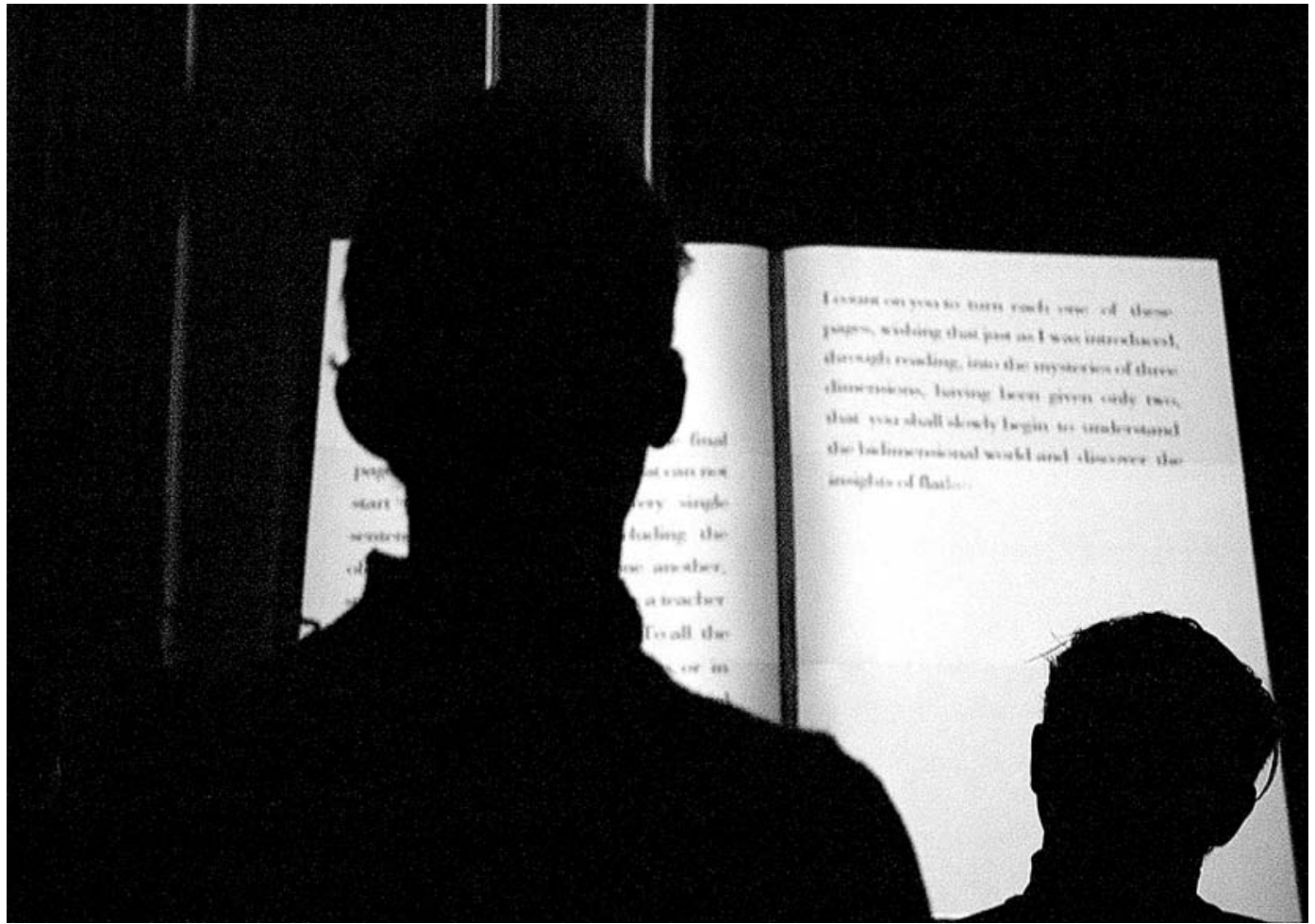

durante a infância nem que as imagens do filme 0 feiticeiro de $\mathrm{Oz}$ (The Wizzard of Oz) sejam uma presença constante. Muito particularmente, a frase com que, num loop, termina esta primeira parte - "there is no place like home" - conduznos para uma ideia de casa, de abrigo protegido de toda a interferência exterior, associada à infância e para onde, de algum modo, todos gostaríamos de regressar. Efectivamente, é lá que estamos durante todo este momento do espectáculo.

Elemento de ligação maior no desenrolar da narrativa e dos seus mil corredores labirinticos, o Homem Plano constata que, para existir, precisa de "pessoas reais", como os espectadores (para ele, note-se, pertencentes à mesma esfera de existência de James Bond...), passiveis de olharem continuamente para ele de modo a poder ganhar vida (= volume e movimento). Tal como no cinema a sequência rápida de imagens estáticas cria um efeito de movimento contínuo, assim também o Homem Plano descobre, nomeadamente através de abundantes referências e citações do cinema no espectáculo, uma fórmula de sair da página bidimensional. Glosando o verso de Shakespeare "ser ou não ser" ( to be or not to be)", o subtítulo do primeiro episódio - "ser é ser visto" (To be is to be seen) - denuncia ironicamente a condição de existência contemporânea ditada pelos media, se quisermos acreditar neles. 0 Homem Plano almeja ser real, logo, ser visto, e, por isso, só no segundo episódio se dará a ver, surgindo inesperadamente por detrás do livro gigante, vestido de smoking e usando os sapatos vermelhos de Dorothy, em 0 feiticeiro de $\mathrm{Oz}$ ) ao som de irónica música ambiente, para raptar o seu público. Ao desafiar a ordem do seu mundo, o Homem Plano desafia simultaneamente a organização do real a 3D, desestabilizando o lugar criado até então para o espectador. Neste momento de transição, o espectadorleitor é evacuado da segurança da casa, do imaginário infantil, para se confrontar com o exterior. Nesse exterior, há um mundo de imagens, de teatros e de actos terroristas que resgata a sua segurança. Transportado num autocarro, o público é levado pela cidade para um local desconhecido e assim tem de ser de modo a potenciar a sensação de "perigo iminente", atestando a similitude de um acto terrorista como um "teatro limite" (ultimate theatre) (palavras do raptor!); as traseiras da Cordoaria Nacional foram, nos espectáculos do Alkantara, um local acertadissimo. Ai, e para manter a sua atenção (visão), éIhe oferecida uma sessão contínua de entretenimento, misturando, num menu similar ao dos dvd's, opções de números de dança, magia, canções e, claro, contos de fadas. Contudo, estes contos não correspondem ao protótipo da moral e da inocência da infância. São contos em que o real invade da forma mais ameaçadora a ficção, embora o pacto do humor e do riso que tipicamente cativa a criança não fique suspenso: na lâmpada de Aladino, o génio é Einstein, cujas fórmulas possibilitaram a criação da bomba atómica; no teatro em Moscovo, o espectáculo a que Elena Yaroshuk assiste é interrompido por um rapto terrorista, facto real da nossa contemporaneidade. Mas não há tempo para contemplações, o espectáculo continua e todo o segundo episódio procede a um ritmo acelerado (lembrando as sequências de montagem MTV), onde não faltam "aplausos enlatados", telefonemas da polícia americana, pizzas, bolinhos e martinis, nem um salvamento em grande apoteose imaginária por um escorrega insuflável, elemento dos salvamentos de desastres de aviões e das mais saudosas brincadeiras da infância.

Só depois de um momento de caos, a nova ordem pode ser estabelecida. No terceiro episódio estamos de regresso ao edifício do teatro (CCB) mas agora num espaço-lounge, descontraído e seguro. Em vez de um livro, o público tem perante si nove écrãs de televisão de onde é emitida uma entrevista com o Homem Plano. Não se volta a ver o actor, apenas a ouvir sua voz, na qualidade de entrevistado de telejornais de todo o mundo que reportam os recentes factos (note-se, por exemplo, a 
subtileza do recurso ao antigo pivot da SIC-noticias, Luis Gouveia Monteiro, para a gravação noticiosa da FLAT TV; o facto de ser reconhecido como jornalista contribui para a ambiguidade/veracidade dos factos reportados). Apesar de reconhecer a "terra do espaço" (spaceland) como um sonho e os seus habitantes como seres imaginários (inventar criaturas de outros planetas são delírios caracteristicos das brincadeiras de crianças), o Homem Plano inventou, supostamente no tempo em que estivemos na parte II, uma máquina para ligar as duas dimensões e tornar possivel uma realidade ideal: a televisão. Claramente, o efeito irónico causado por esta conclusão não se prende apenas com o engenho inteligente de Portela, mas também com o facto de ele revelar a concepção actual do mundo como uma infinitude de imagens plurais e fragmentárias. Nesta visão, o mundo já não nos é dado a decifrar, mas é-nos oferecido à contemplação passiva de algo irreversivelmente construído por outros: a imagem do mundo é o mundo; deixámos de a decifrar, de participar do seu segredo, e passámos a desconstruí-la, olhando-a do lado de fora da janela. Neste momento, desvanece-se a pertença à comunidade de leitores-espectadores que ocupou e assistiu aos acontecimentos do espectáculo. Por esta razão, o espaço anónimo de um átrio do CCB não poderia ser mais oportunamente frio e esvaziado de sentido e a acção dramática reenviada com maior propriedade para dentro das caixas mágicas. Este final descendente, instaura propositadamente uma estranheza no espectador, que Ihe fica gravado no íntimo. Depois de uma parte de deslumbramento e de outra de perturbação, a força da anterior pertença faz-se sentir por oposição à contemplação individual da imagem televisiva (ainda que repleta de pequenos detalhes divertidissimos, com aparições subtis do ficcional Homem Plano). 0 contraste é, porém, atenuado quando o Homem Plano, na sua inocência efabulada, desmistifica o fundo dessa planura televisiva: a sua realidade, como a de todas as realidades, alicerça-se numa questão de crença: "ver é acreditar e acreditar é ver" (seeing is believing and believing is seeing). Imagem televisiva ou página de um livro, ambas só existem enquanto realidade na medida em que existe o poder de as imaginar, logo, de as criar; uma vez criadas pelo espirito, elas poderão ser inscritas no real. Sendo o espirito condição primeira para a existência da realidade, então ele assegura a criação de tantas realidades quantas desejar.

Do mais ínfimo detalhe (ex: a distribuição das capas de isolamento térmico, na operação de salvamento) até à macro-organização por episódios (ex: livro, performance, televisão), nada é deixado ao acaso. Flatland é um exemplo magistral de coerência e eficácia dramatúrgica, circunscrevendo um lugar crítico e construtivo, autêntico e aberto; por outras palavras, um lugar essencial.

Colocando o espectador na posição simultânea de leitor, a experiência do espectáculo torna-se numa participação e pertença duplas: por um lado, faz parte da comunidade real de espectadores-vítimas que assistem em determinado dia e local à trilogia Flatland, por outro, pertence a um comunidade imaginada, a uma "imagem pairante", nas palavras de Filomena Molder. A experiência estética que Flatland nos proporciona consiste em nos transportar para este estado imagético, "mover-nos com" ele através do seu labirinto sedutor, guiados por uma "vidência" encenada que rememora o encantamento da leitura, que nos concilia com a nossa verdade essencial de fabricadores do real. Por isso, nos "comove".

Em Flatland, a participação inevitável do espectador implica a sua imersão lúdica em questões fulcrais da contemporaneidade: leva-nos a questionar a dificuldade com que gerimos a abundância da informação, do poder de quem a veicula e porque lhe damos tamanho crédito; leva-nos a repensar o modo como as coisas são ou se nos apresentam e como gostariamos que fossem; leva-nos a perguntar o que será efectivamente essencial para cada um de nós, em que plano de realidade queremos viver; leva-nos a construir uma consciência de agentes implicados na crença e na criação do real. E, sobretudo, Flatland transporta-nos para um lugar que conhecemos, que nos é próximo mas talvez esteja adormecido. 0 imaginário infantil e os códigos de leitura motivam o encantamento e o sentido de pertença ao redescobrir em nós a capacidade, simultaneamente criadora e descodificadora do real. Tratase, portanto, de uma viagem ao interior de cada um de nós, da qual regressamos revigorados e confiantes sem recorrermos necessariamente a uma racionalização do acontecido. Nesse lugar, fortalecemos o encontro com uma profunda e esquecida memória de nós.

[0] leitor não é tanto aquele que vê, quanto aquele que a vidência guia, esquecido da sua própria visibilidade. Maria Filomena Molder (1999:19).

\section{Referência bibliográfica}

MOLDER, Maria Filomena (1999), Semear na neve, Relógio D'Água, Lisboa. 